\title{
Nexus Between Tuberculosis and Diabetic Mellitus, A Prospective Cohort Study.
}

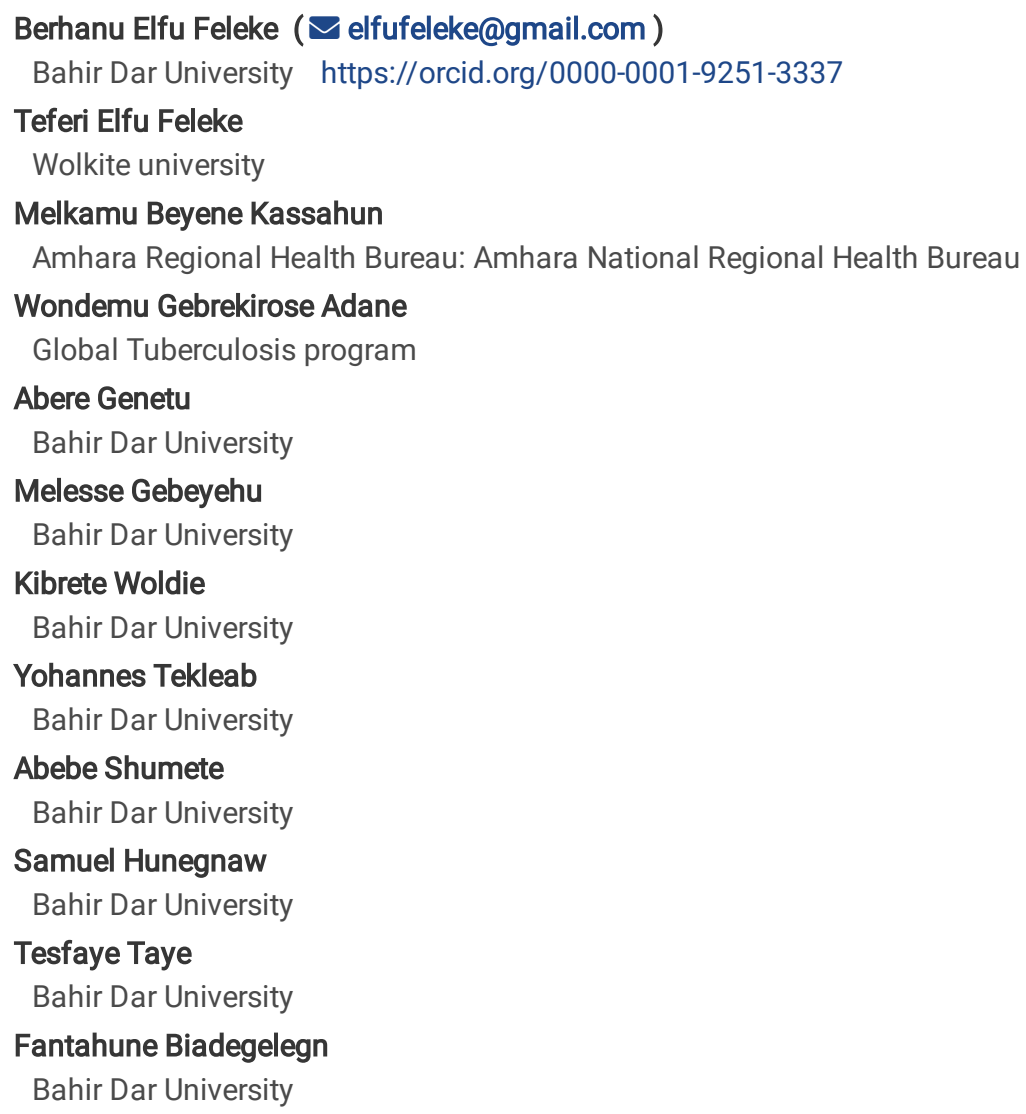

Research article

Keywords: Diabetes Mellitus, Tuberculosis, treatment outcome, lipid profiles, DOTS

Posted Date: November 2nd, 2020

DOI: https://doi.org/10.21203/rs.3.rs-100166/v1

License: (c) (i) This work is licensed under a Creative Commons Attribution 4.0 International License. Read Full License 


\section{Abstract}

Background: This work aimed to describe the clinical presentation of TB in patient with DM, to determine the effects of DM on TB treatment outcomes, to identify the effects of TB on glycemic control, and to describe the lipid profile of TB and DM patients.

Methods: This prospective cohort study design was conducted. The data were collected from September 2018 to June 2020 using patient interviews, examining the patients, chart review, and collecting blood samples. Binary logistic regression was used to identify the determinants of TB treatment outcomes in the context of DM. Kaplan Meier survival curve was used to see the effects of DM on TB clinical response. Linear regression was used to identify the determinants of the $\mathrm{HbA} 1 \mathrm{c}$ level during TB infection.

Results: A total of 1092 study participants were included giving for the response rate at $93.81 \%$. Good TB treatment outcome was observed in $72.5 \%$ of the patients [95\% Cl: $69 \%$ - 76 \%]. The odds of good TB treatment outcomes were at $75 \%$ lower in the presence of DM (AOR 0.25 [95 \% $\mathrm{Cl}: 0.08-0.73]$ ). The median time of clinical response in TB and DM patients was 45 days interquartile range (IQR) of 8 days; the median time of clinical response in DM free TB patients was 9 days [IQR 2 days]. TB increased the HbA1c level of DM patients by $1.22 \%$ (B 1.22 [95\% Cl: $1.11-$ 1.34]). In six months period, $60 \%$ of TB and DM patients had got 3 episodes of acute complications.

Conclusion: DM significantly decreases the favorable treatment outcome of DOTS. TB predisposed DM patients for bad glycemic control and increased episodes of acute DM complications.

\section{Background}

Diabetes mellitus (DM) is a metabolic disorder characterized by the defects of insulin action, secretion, or a combination of both [1]. DM is classified as type 1 and type 2, the type $2 \mathrm{DM}$ is the most common type reported [2]. World health organization (WHO) estimates that more than 422 million people are living with DM and a total of 1.6 million people died from DM [3]. The situation seriously affecting the low and middleincome countries, in Africa an estimated 19 million people were living with diabetes $[4,5]$. In Ethiopia, about 1.7 million people were living with diabetes [6].

Tuberculosis (TB) is a chronic infectious disease caused by Mycobacterium species mostly affecting the lung. Each year, TB affects 10 million people and a total of 1.5 million people died from TB [7]. The burden of TB was higher in resource-limited settings. In Ethiopia, the incidence of TB was 151 per 100000 population, and killing 22 individuals per 100000 people [8].

The association between DM and TB is bidirectional. TB increases the risk of DM and DM increases the risk of TB. About 15\% of the world's TB cases were attributed by DM $[9,10]$. DM decreases cell-mediated immunity, alveolar macrophage, pulmonary microangiopathy, micronutrient deficiency that finally predisposes the patients to acquire TB [11]. TB induces disturbance in the endocrine action of insulin creating a favorable environment to the DM pathogenesis [12].In the resource-limited settings, there is limited information on the effects of DM on TB and the reverse effects of TB on DM.

Therefore, this study aimed to describe the clinical presentation of TB during DM, to determine the effects of DM on TB treatment outcomes, to identify the effects of TB on glycemic control, and to describe the lipid profile of TB and DM patients.

\section{Methods}

A prospective cohort study design was implemented. The study was conducted in the referral hospitals of the Amhara regional state; the region contains 5 referral hospitals namely, Gondar University hospital, Felegehiwote referral hospital, Dessie referral hospital, Debreberhane referral hospital, and Debremarkose referral hospital. The data were collected from September 2018 to June 2020. The data were collected using patient interviews, examining the patients, chart review, and collecting the blood samples. Blood samples were collected and analyzed by trained laboratory technologists. The trained medical doctors participated in data collection. Initially, baseline data were collected from each study participant; then, update data for TB clinical response and adverse drug reaction were collected every week. The episodes of acute DM complications were collected every month. Every six months, we measured the functional status, lipid profiles, and micronutrient levels of the study participants. An International physical activity questionnaire (IPAQ) was used to measure regular physical activity [13]. Medication adherence was measured using the ten-item medication adherence scale (MARS)[14]. High-performance liquid chromatography was used to measure the hemoglobin A one $\mathrm{C}(\mathrm{HbA} 1 \mathrm{c})$ level of the patients and its value above $7 \%$ indicates bad glycemic control [15]. Problematic alcohol use was screened using the CAGE tool[16]. Good TB treatment outcome was declared if the patient completed the treatments or become smearnegative at the end of DOTS. High-performance liquid chromatography was used to measure the serum vitamin A level of the patient [17], Serum zinc level was measured using atomic absorption spectrophotometer [18, 19], mini Vitek Immune Diagnostic Assay System (VIDAS) machine was used to measure the serum vitamin D level. The functional status questionnaire was used to measure the functional status of the patients [20]. Serum Ferritin was measured using ELISA adhering to the manufacturer's instruction. Lipid profile of the patient was measured using the Cobas Integra 400 Plus clinical chemistry machine (Roche, Switzerland) [21]. Serum albumin was measured using a dye-binding method [22]. 
The eligibility criteria for this study were DM or TB patients having a regular follow up at the referral hospitals of the region. The study participants unwilling to give consent for the study were excluded. The quality of the study was maintained by conducting a pretest and providing training to the data collectors and supervisors. In addition, the standard operating procedures were adhered to during the laboratory data collection. The sample size was calculated using Epi-info software with the assumption of $95 \% \mathrm{Cl}$, power of $80 \%$, a risk ratio of 0.8 , TB and DM to DM or TB patients ratio of 2, and non-response rate of $10 \%$ gives 1164 study participants (388 DM and TB patients, 388 DM free TB patients, and 388 TB free DM patients). The simple random sampling technique was used to select the study participants using their TB or DM registration ID as a sampling frame. Data were entered into the computer using EPI-info software and transferred to the STATA version 14 for the analysis. Descriptive statistics were used to describe the profiles of study participants. Binary logistic regression was used to identify the determinants of TB treatment outcomes in the context of DM. Kaplan Meier survival curve was used to see the effect of DM on TB clinical response. Linear regression was used to identify the determinants of the HbA1c level during TB infection. The paired t-test was used to see the effects of DOTS on lipid and micronutrient levels of the patients. Multiple imputation method was used to handle the missing data.

Ethical clearance was obtained from Bahir Dar University College of Medicine and Health sciences ethical review board (Ethical application number CMHS/IRB/124/2018). A support letter was obtained from Amhara national regional state health bureau and respective hospitals. Written informed consent was obtained from each study participant. Study participants with abnormal laboratory findings were linked to the curative segment.

\section{Results}

A total of 1092 study participants were included in the study. The response rate was $93.81 \%$. Twenty-six patients were excluded because of lowquality laboratory samples, 34 study participants were excluded because of their consent, and 12 study participants were excluded because of loss to follow up. The mean age of the study participants was at 32.63 years [SD \pm 15.79 years] with the lowest age of the study subjects at 18 years (Table 1$)$.

Table 1

Profiles of the study participants $(n=1092)$.

\begin{tabular}{|c|c|c|c|c|c|c|c|}
\hline Variables & & \multicolumn{2}{|c|}{ TB free DM patients $(\mathrm{n}=358)$} & \multicolumn{2}{|c|}{ TB and DM patients $(n=361)$} & \multicolumn{2}{|c|}{ DM free TB patients (373) } \\
\hline \multirow[t]{2}{*}{ Family size } & $>4$ & 194 & 54.2 & 350 & 97 & 353 & 94.6 \\
\hline & $\leq 4$ & 164 & 45.8 & 11 & 3 & 20 & 5.4 \\
\hline Sex & Female & 105 & 29.3 & 116 & 32.1 & 283 & 75.9 \\
\hline \multirow[t]{2}{*}{ Regular physical exercise } & Present & 161 & 45 & 94 & 26 & 257 & 68.9 \\
\hline & Absent & 197 & 55 & 267 & 74 & 116 & 31.1 \\
\hline Residence & Urban & 180 & 50.3 & 177 & 49 & 156 & 41.8 \\
\hline \multirow[t]{3}{*}{ Marital status } & Single & 88 & 24.6 & 206 & 57.1 & 197 & 52.8 \\
\hline & Married & 268 & 74.9 & 152 & 42.1 & 174 & 46.8 \\
\hline & Others & 2 & 0.6 & 3 & 0.9 & 2 & 0.5 \\
\hline \multirow[t]{2}{*}{ Age } & $\geq 45$ & 53 & 14.8 & 75 & 20.8 & 76 & 20.4 \\
\hline & $<45$ & 305 & 85.2 & 286 & 79.2 & 297 & 79.6 \\
\hline
\end{tabular}

\section{Tuberculosis in diabetes mellitus patients}

A total of 734 TB patients were followed for 6 months; good TB treatment outcome was observed in $72.5 \%$ of the patients [95\% Cl: $69 \%$ - $76 \%$ ]. After adjusting for age, sex, type of TB, DM, family size, problematic alcohol use, physical exercise, HIV, and marital status; TB treatment outcomes were determined by DM, family size, sex, regular physical exercise, HIV, and problematic alcohol use (Table 2). 
Table 2

Determinants of TB treatment outcome $(n=734)$.

\begin{tabular}{|c|c|c|c|c|c|c|}
\hline \multirow[t]{2}{*}{ Variables } & & \multicolumn{2}{|c|}{ TB prognosis } & \multirow[t]{2}{*}{$\operatorname{COR}^{1}[95 \% \mathrm{Cl}]$} & \multirow[t]{2}{*}{$\mathrm{AOR}^{2}[95 \% \mathrm{Cl}]$} & \multirow[t]{2}{*}{ P-value } \\
\hline & & Good & Bad & & & \\
\hline \multirow[t]{2}{*}{ DM } & Present & 176 & 185 & \multirow[t]{2}{*}{$0.05[0.03-0.08]$} & \multirow[t]{2}{*}{$0.25[0.08-0.73]$} & \multirow[t]{2}{*}{0.01} \\
\hline & Absent & 356 & 17 & & & \\
\hline \multirow[t]{2}{*}{ Sex } & Male & 211 & 124 & \multirow[t]{2}{*}{$0.41[0.29-0.58]$} & \multirow[t]{2}{*}{$1.78[1.1-2.87]$} & \multirow[t]{2}{*}{0.01} \\
\hline & Female & 321 & 78 & & & \\
\hline \multirow[t]{2}{*}{ Family size } & $>4$ & 182 & 188 & \multirow[t]{2}{*}{$0.04[0.02-0.07]$} & \multirow[t]{2}{*}{0.19 [0.07-0.59] } & \multirow[t]{2}{*}{$<0.01$} \\
\hline & $\leq 4$ & 350 & 14 & & & \\
\hline \multirow[t]{2}{*}{ Problematic alcohol use } & Present & 173 & 122 & \multirow[t]{2}{*}{$0.32[0.23-0.44]$} & \multirow[t]{2}{*}{$0.55[0.36-0.84]$} & \multirow[t]{2}{*}{$<0.01$} \\
\hline & Absent & 359 & 80 & & & \\
\hline \multirow[t]{2}{*}{ Residence } & Urban & 252 & 81 & \multirow[t]{2}{*}{$1.34[0.97-1.87]$} & \multirow[t]{2}{*}{$1.68[1.1-2.55]$} & \multirow[t]{2}{*}{0.01} \\
\hline & Rural & 280 & 121 & & & \\
\hline \multirow[t]{2}{*}{ HIV } & Positive & 93 & 121 & \multirow[t]{2}{*}{$0.14[0.09-0.2]$} & \multirow[t]{2}{*}{$0.32[0.21-0.49]$} & \multirow[t]{2}{*}{$<0.01$} \\
\hline & Negative & 439 & 81 & & & \\
\hline \multirow[t]{2}{*}{ Regular physical exercise } & Present & 302 & 49 & \multirow[t]{2}{*}{$4.09[2.85-5.9]$} & \multirow[t]{2}{*}{$1.69[1.04-2.76]$} & \multirow[t]{2}{*}{0.03} \\
\hline & Absent & 230 & 153 & & & \\
\hline
\end{tabular}

${ }^{1} \mathrm{COR}=$ crude odds ratio

${ }^{2} \mathrm{AOR}=$ adjusted odds ratio

\section{Interpretation for Table 2}

The odds of good TB treatment outcomes were 75\% lower in the presence of DM (AOR 0.25 [95\% Cl: $0.08-0.73]$ ). The odds of good treatment outcome in males were found to be 1.78 folds higher than in the female participants (AOR 1.78 [95\% Cl: 1.1-2.87]). Higher family size decreased the odds of good treatment outcome by $81 \%$ (AOR 0.19 [95\% Cl: 0.07-0.59]). Problematic alcohol use lowered the odds of good treatment outcome by $45 \%$ (AOR 0.55 [95\% Cl: $0.36-0.84]$ ). Good treatment outcomes among urban TB patients were at 1.68 folds higher than rural TB patients (AOR 1.68 [95\% Cl: 1.1-2.55]). HIV infection lowered the odds of good TB treatment outcomes by $68 \%$ (AOR 0.32 [95\% Cl: $0.21-0.49]$ ).

The clinical profile of TB during DM deviated from the classical TB; the proportion of extra-pulmonary TB was at $75.9 \%$ and $55.11 \%$ of extrapulmonary TB was severe, $39.6 \%$ of TB presentation was atypical (Table 3 ).

Table 3

Clinical presentation of TB in DM patients $(n=734)$

\begin{tabular}{|c|c|c|c|c|c|}
\hline \multirow[t]{2}{*}{ Variables } & & \multicolumn{2}{|c|}{ DM patients (361) } & \multicolumn{2}{|c|}{ DM free patients (373) } \\
\hline & & Frequency & $\%$ & Frequency & $\%$ \\
\hline \multirow[t]{2}{*}{ Type of TB } & Pulmonary & 87 & 24.1 & 188 & 50.4 \\
\hline & Extra pulmonary & 274 & 75.9 & 185 & 49.6 \\
\hline \multirow[t]{2}{*}{ Severity of extra pulmonary TB } & Severe & 151 & 55.11 & 56 & 31.11 \\
\hline & Not severe & 123 & 44.89 & 124 & 68.89 \\
\hline \multirow[t]{2}{*}{ Atypical TB presentation } & Present & 143 & 39.6 & 15 & 4 \\
\hline & Absent & 218 & 60.4 & 358 & 96 \\
\hline \multirow[t]{2}{*}{ Adverse drug reaction } & Present & 56 & 15.5 & 31 & 8.3 \\
\hline & Absent & 305 & 84.5 & 342 & 91.7 \\
\hline \multirow[t]{2}{*}{ Hepatotoxicity } & Present & 10 & 2.77 & 2 & 0.54 \\
\hline & Absent & 351 & 97.33 & 371 & 99.46 \\
\hline
\end{tabular}

Page $4 / 12$ 
The clinical response of DM and TB patients were significantly delayed as compared to DM free TB patients. The median time of clinical response in TB and DM patients was 45 days interquartile range (IQR) of 8 days; the median time of clinical response in DM free TB patients was 9 days [IQR 2 days].(Fig. 1).

\section{Diabetes mellitus in the context of Tuberculosis}

719 DM patients were included. The mean HbA1c level of the patients was at $7.56 \%$ [SD $\pm 1.12 \%]$. The mean $\mathrm{HbA} 1 \mathrm{c}$ level of TB free DM patients was at $6.81 \%$ [SD $\pm 0.38 \%$ ]; the mean $\mathrm{HbA} 1 \mathrm{c}$ level of DM patients with TB cases was found to be at $8.31 \%$ [SD $\pm 1.12 \%]$.

The glycemic control was good in $40.8 \%$ [95\% Cl: $37.15 \%-44.35 \%$ ] of the patients. Glycemic control was good in $64 \%$ [95\% Cl: $58.97 \%-68.96 \%$ ] of TB free DM patients; the glycemic control was good in 17.7\% [95\% Cl: $13.77 \%-21.69 \%$ of DM patients with TB infection. After adjusting for TB, sex, regular physical activity, medication adherence scale, DM duration, DM type, age, Hypertension, HIV, family size, residence; the HbA1C level of DM patient was determined by TB, sex, regular physical activity, medication adherence scale, DM duration, DM type, age, Hypertension (Table 4).

Table 4

The Determinants of HbA1c level in DM patients $(n=719)$.

\begin{tabular}{|c|c|c|c|c|c|}
\hline \multirow[t]{2}{*}{ Variables } & \multirow[t]{2}{*}{ B } & \multirow[t]{2}{*}{$t$} & \multirow[t]{2}{*}{ P-value } & \multicolumn{2}{|c|}{$95.0 \%$ Confidence Interval for B } \\
\hline & & & & Lower Bound & Upper Bound \\
\hline TB & 1.22 & 21.65 & $<0.01$ & 1.11 & 1.34 \\
\hline Sex & 0.12 & 2.98 & $<0.01$ & 0.04 & 0.20 \\
\hline Regular physical exercise & -0.12 & -2.93 & $<0.01$ & -0.20 & -0.04 \\
\hline Medication Adherence Scale & -0.28 & -18.46 & $<0.01$ & -0.31 & -0.25 \\
\hline DM type & -0.44 & -8.93 & $<0.01$ & -0.54 & -0.34 \\
\hline Age & 0.00 & 2.45 & 0.01 & 0.00 & 0.01 \\
\hline DM duration & 0.06 & 11.57 & $<0.01$ & 0.05 & 0.07 \\
\hline Hypertension & 0.18 & 3.57 & $<0.01$ & 0.08 & 0.27 \\
\hline
\end{tabular}

\section{Interpretation of Table 4}

TB increased the HbA1c level of DM patients by $1.22 \%$ (B 1.22 [95\% Cl: 1.11-1.34]). The HbA1c level of male DM patients was $0.12 \%$ higher than female DM patients (B 0.12 [95\% Cl: 0.04-0.2]). We observed that the regular physical exercise decreased the HbA1c level of DM patients by $0.12 \%$ (B - 0.12 [95\% Cl: 0.04-0.2]). Per one unit increase in the medication adherence scale, the HbA1c level of DM patient decreases by $-0.28 \%$ (B 0.28 [95\% Cl: $0.25-0.31]$ ). The HbA1c level of type $2 \mathrm{DM}$ patients was $0.44 \%$ lower than type $1 \mathrm{DM}$ patients (B 0.44 [95\% Cl: $0.34-0.54]$ ). Per a year increase in the duration of DM, the HbA1c level increases by $0.06 \%$ (B 0.06 [95\% Cl: 0.05-0.07]).

The episodes of acute DM complications have been assessed in this study. Thus, TB patients with DM had frequent episodes of acute complications than with TB free DM patients, $60 \%$ of TB and DM patients had 3 episodes of acute complications in 6 months period (Table 5 ).

Table 5

Episodes of acute diabetic complications in the context of DM ( $n=719)$

\begin{tabular}{|lllll|}
\hline \multirow{2}{*}{ Acute DM complications episodes } & \multicolumn{2}{l}{ TB free DM patients $(\mathbf{n}=\mathbf{3 5 8})$} & \multicolumn{2}{l|}{ DM patients with TB infection $(\mathbf{n}=\mathbf{3 6 1})$} \\
\cline { 2 - 5 } & Frequency & $\%$ & Frequency & $\%$ \\
\hline 0 & 304 & 84.9 & 25 & 6.9 \\
\hline 1 & 46 & 12.8 & 37 & 10.2 \\
\hline 2 & 4 & 1.1 & 81 & 22.4 \\
\hline 3 & 4 & 1.1 & 217 & 60.1 \\
\hline 4 & 0 & 0 & 1 & 0.3 \\
\hline
\end{tabular}


DM patients with TB infection have lower baseline micronutrient and lipid profile compared to TB or DM patients; after 6 months the micronutrient level and lipid profile was not increasing to the sufficient level for DM and TB patients (Table 6).

Table 6

Lipid and micronutrient profiles of the study participants $(n=1092)$

\begin{tabular}{|c|c|c|c|c|c|c|c|c|c|}
\hline \multirow[t]{2}{*}{ Profiles } & \multicolumn{3}{|c|}{ DM patients without TB $(n=358)$} & \multicolumn{3}{|c|}{ TB and DM patients $(n=361)$} & \multicolumn{3}{|c|}{ TB patients without DM (373) } \\
\hline & Baseline & After 6 months & P-value & Baseline & After 6 months & P-value & Baseline & After 6month & P-value \\
\hline Vitamin $A$ in $\mu \mathrm{g} / \mathrm{dl}^{3}$ & 37.54 & 37.09 & 0.09 & 27.42 & 30.06 & $<0.01$ & 31.97 & 38.96 & $<0.01$ \\
\hline Zinc in $\mu \mathrm{g} / \mathrm{dl}$ & 93.94 & 103.99 & $<0.01$ & 82.39 & 88.80 & $<0.01$ & 90.87 & 93.39 & $<0.01$ \\
\hline Vitamin $\mathrm{D}$ in $\mathrm{ng} / \mathrm{dl}^{4}$ & 23.09 & 26.03 & $<0.01$ & 19.78 & 20.87 & $<0.01$ & 20.33 & 27.80 & $<0.01$ \\
\hline Ferritin in $\mathrm{ng} / \mathrm{ml}$ & 29.66 & 30.45 & $<0.01$ & 14.88 & 15.69 & $<0.01$ & 18.88 & 23.32 & $<0.01$ \\
\hline Albumin in $\mathrm{g} / \mathrm{dl}^{5}$ & 3.52 & 3.52 & 0.63 & 2.88 & 3.05 & $<0.01$ & 3.00 & 3.37 & $<0.01$ \\
\hline $\mathrm{TCL}$ in $\mathrm{mg} / \mathrm{dl}^{6}$ & 223.43 & 236.46 & $<0.01$ & 200.63 & 203.85 & $<0.01$ & 176.78 & 187.11 & $<0.01$ \\
\hline $\mathrm{TGL}$ in $\mathrm{mg} / \mathrm{dl}$ & 163.97 & 145.52 & $<0.01$ & 107.22 & 116.43 & $<0.01$ & 108.06 & 105.29 & 0.36 \\
\hline $\mathrm{HDL}$ in $\mathrm{mg} / \mathrm{dl}$ & 41.69 & 44.94 & $<0.01$ & 34.17 & 34.67 & $<0.01$ & 43.49 & 49.86 & $<0.01$ \\
\hline LDL in $\mathrm{mg} / \mathrm{dl}$ & 148.95 & 162.42 & $<0.01$ & 145.02 & 145.89 & 0.15 & 111.69 & 116.19 & $<0.01$ \\
\hline
\end{tabular}

${ }^{3}$ Microgram per deciliter

${ }^{4}$ Nanogram per deciliter

${ }^{5}$ Gram per deciliter

${ }^{6}$ Milligram per deciliter

The baseline functional status of TB and DM patients was poor, after 6 months, the functional status of TB and DM patients did not improve sufficiently (Table 7). 
Table 7

Functional status of the study participants $(n=1092)$

\begin{tabular}{|c|c|c|c|c|c|c|c|c|c|c|c|c|}
\hline \multirow[t]{3}{*}{ Parameter } & \multicolumn{4}{|c|}{ Without TB DM patients(n = 358) } & \multicolumn{3}{|c|}{ TB and DM patients $(n=361)$} & \multicolumn{4}{|c|}{ TB patients without DM (373) } & \\
\hline & \multicolumn{2}{|l|}{ Good } & \multicolumn{2}{|c|}{ warning zone } & \multirow{2}{*}{$\begin{array}{l}\text { Good } \\
\text { Frequency }\end{array}$} & \multicolumn{2}{|c|}{ warning zone } & \multicolumn{2}{|c|}{ Good } & \multicolumn{3}{|c|}{ waming zone } \\
\hline & Frequency & $\%$ & frequency & $\%$ & & $\%$ & Frequency & $\%$ & Frequency & $\%$ & Frequency & $\%$ \\
\hline $\begin{array}{l}\text { Baseline } \\
\text { basic } \\
\text { activities of } \\
\text { daily living }\end{array}$ & 128 & 35.8 & 230 & 64.2 & 50 & 13.9 & 311 & 86.1 & 163 & 43.7 & 210 & 56.3 \\
\hline $\begin{array}{l}\text { After } 6 \\
\text { months } \\
\text { basic } \\
\text { activities of } \\
\text { daily living }\end{array}$ & 126 & 35.2 & 232 & 64.8 & 92 & 25.5 & 269 & 74.5 & 328 & 87.9 & 45 & 12.1 \\
\hline $\begin{array}{l}\text { Intermediate } \\
\text { activity of } \\
\text { basic living } \\
\text { at baseline }\end{array}$ & 200 & 55.9 & 158 & 44.1 & 50 & 13.9 & 311 & 86.1 & 292 & 78.3 & 81 & 21.7 \\
\hline $\begin{array}{l}\text { Intermediate } \\
\text { activity of } \\
\text { basic living } \\
\text { after } 6 \\
\text { months }\end{array}$ & 201 & 56.1 & 157 & 43.9 & 221 & 61.2 & 140 & 38.8 & 352 & 94.4 & 21 & 5.6 \\
\hline $\begin{array}{l}\text { Mental } \\
\text { health at } \\
\text { baseline }\end{array}$ & 256 & 71.5 & 102 & 28.5 & 81 & 22.4 & 280 & 77.6 & 317 & 85 & 56 & 15 \\
\hline $\begin{array}{l}\text { Mental } \\
\text { health after } \\
6 \text { months }\end{array}$ & 257 & 71.8 & 101 & 28.2 & 215 & 59.6 & 146 & 40.9 & 358 & 96 & 15 & 4 \\
\hline $\begin{array}{l}\text { Work } \\
\text { performance } \\
\text { at baseline }\end{array}$ & 200 & 55.9 & 158 & 44.1 & 50 & 13.9 & 311 & 86.1 & 292 & 78.3 & 81 & 21.7 \\
\hline $\begin{array}{l}\text { Work } \\
\text { performance } \\
\text { after } 6 \\
\text { months }\end{array}$ & 198 & 55.3 & 160 & 44.7 & 175 & 48.5 & 186 & 51.5 & 349 & 93.6 & 24 & 6.4 \\
\hline $\begin{array}{l}\text { Social } \\
\text { activities at } \\
\text { baseline }\end{array}$ & 200 & 55.9 & 158 & 44.1 & 50 & 13.9 & 311 & 86.1 & 292 & 78.3 & 81 & 21.7 \\
\hline $\begin{array}{l}\text { Social } \\
\text { activities } \\
\text { after } 6 \\
\text { months }\end{array}$ & 198 & 55.3 & 160 & 44.7 & 175 & 48.5 & 186 & 51.5 & 349 & 93.6 & 24 & 6.4 \\
\hline $\begin{array}{l}\text { Quality of } \\
\text { interaction } \\
\text { at baseline }\end{array}$ & 256 & 71.5 & 102 & 28.5 & 81 & 22.4 & 280 & 77.4 & 317 & 85 & 56 & 15 \\
\hline $\begin{array}{l}\text { Quality of } \\
\text { interaction } \\
\text { after } 6 \\
\text { months }\end{array}$ & 292 & 81.6 & 66 & 18.4 & 219 & 60.7 & 142 & 39.2 & 360 & 96.5 & 13 & 3.5 \\
\hline
\end{tabular}

\section{Discussion}

In this study we observed good TB treatment outcome at $72.5 \%$ of the study patients [95\% Cl: $69 \%-76 \%]$, the good TB treatment outcome for DM free TB patients was at $95.4 \%$, only $48.8 \%$ of the DM and TB patients have good treatment outcome; The odds of good TB treatment outcome were $75 \%$ lower in the presence of DM. This finding agrees with the research conducted in Indonesia [23]. This is due to the high Mycobacterium burden leading to a longer time for culture conversion[24]. Additionally, DM affects the pharmacokinetics of anti-TB drugs by reducing their plasma concentration [25].

The proportion of pulmonary TB was lower in the presence of DM, only $24.1 \%$ of the TB cases were pulmonary and $55.11 \%$ of them were extrapulmonary TB which was found to be very severe. This finding was in-line with the findings in Georgia [26]. This is due to the effects of DM on the 
smear production and excretion that affects the detection of TB, indicating that a significant number of pulmonary TB was not detected in DM patients [27].

Atypical TB was common in DM patients reaching $40 \%$ of the TB patients. This finding is consistent with the findings in Brazil [28]. This indicates that the TB diagnostic algorithm should be revised in the case of DM as reported with the study in India [29].

In this study, $15.5 \%$ of the DM patients manifested with adverse TB reaction compared to $8.3 \%$ of the adverse drug reaction in TB patients without DM. The reason might be due to the high pills burden of TB-DM patients that finally predisposed the patients for the adverse drug reactions [30].

In this study, the median time of clinical response in TB and DM patients was 45 days, interquartile range (IQR) of 8 days; the median time of clinical response in DM free TB patients was 9 days [IQR 2 days]. This is consistent with the previous report in Ethiopia [31], suggesting that the treatment algorithm should be revised in TB-DM patients in Ethiopia.

In our study, we observed that TB increased the $\mathrm{HbA} 1 \mathrm{c}$ level of DM patients by $1.22 \%$. The mean $\mathrm{HbA} 1 \mathrm{c}$ level of the patients was at $7.56 \%$ [SD \pm $1.12 \%]$. The mean $\mathrm{HbA} 1 \mathrm{c}$ level of TB free DM patient was $6.81 \%$ [SD $\pm 0.38 \%$; the mean $\mathrm{HbA} 1 \mathrm{c}$ level of DM patients with TB was $8.31 \%$ [SD \pm $1.12 \%]$. The glycemic control was good in $40.8 \%$ [95\% Cl: $37.15 \%-44.35 \%$ ] of the patients. Glycemic control was good in $64 \%$ [95\% Cl: $58.97 \%-$ $68.96 \%$ ] of TB free DM patients; the glycemic control was good in $17.7 \%$ [95\% Cl: $13.77 \%-21.69 \%$ ] of DM patients with TB infection. This finding agrees with the findings in India [32]. This is due to the reason that TB induces glucose intolerance worsening the glycemic control of DM patients [33].

In our study, we observed that excess episode of acute DM complications in DM and TB patients; in the 6 months period, $60 \%$ of the TB and DM patients which had found to be 3 episodes of acute complications compared to $15 \%$ of cumulative complications in TB free DM patients. This finding is comparable with the finding in Mexico [34]. This is be due to the effects of infection on inducing the stress hormones that disturbs insulin metabolism [35, 36].

After DOTS completion, Vitamin A increased by $2.65 \mu \mathrm{g} / \mathrm{dl}$ for DM and TB patients, as compared to $7 \mu \mathrm{g} / \mathrm{dl}$ increment for DM free TB patients. This strengthens the justification that, higher complications rate of DM among TB patients was attributed to low vitamin A level.

The baseline serum zinc level of DM and TB patients was $88.23 \mu \mathrm{g} / \mathrm{dl}$, while the baseline serum zinc level of DM free TB patients was $90.87 \mu \mathrm{g} / \mathrm{dl}$. This finding agrees with findings from India [37]. This will strengthen the necessity of zinc supplementation for DM patients [38].

In this study, vitamin D increased by $1.1 \mathrm{ng} / \mathrm{dl}$ for DM and TB patients, and its values increased by $7.46 \mathrm{ng} / \mathrm{dl}$ for DM free TB patients. This finding agrees with the finding in Korea [39]. This finding implies that the critical role of vitamin D was limited in TB-DM patients.

The study indicated that the baseline Ferritin level of DM and TB patients was $14.88 \mathrm{ng} / \mathrm{ml}$ whereas the baseline Ferritin level of DM free TB patients was $18.88 \mathrm{ng} / \mathrm{ml}$. The finding was consistent with previously available literature regarding the association between DM and Ferritin. This is due to the high burden of anemia in our study areas [40].

In our study we observed that the HDL level of DM and TB patients was at $34.17 \mathrm{mg} / \mathrm{dl}$, the baseline HDL level of DM free TB patients was at $43.49 \mathrm{mg} / \mathrm{dl}$. The finding was in line with the finding in Netherland [41], suggesting high malnutrition burdens in the study area [42].

In DM and TB group, the basic activity of daily living was improved by $11.6 \%$ for the good zone, $44.5 \%$ increment for the good zone was observed in DM free TB patients. This finding is in agreement with the findings in Netherland [43]. This urgently calls great attention of decision-makers to revise the management of the two morbidities during co-existence.

The main limitation of this research work was a failure to identify the effects of TB on the chronic complications of DM and the effect of DM on the relapse of TB.

\section{Conclusion}

In the studied region, we observed DM significantly decreased the favorable treatment outcome of DOTS. DM makes the TB presentation atypical and delays the clinical response and disturbs the lipid and micronutrient profiles of TB patients. TB predisposes the DM patients for bad glycemic control and increased the episodes of acute DM complications. Furthermore, TB decreased the functional status of DM patients.

\section{Abbreviations}

- $\mu \mathrm{g} / \mathrm{dl}$ : Microgram per deciliter

- AOR: Adjusted odds ratio

- B: Beta coefficient 
- $\mathrm{Cl}$ : confidence interval

- COR : Crude odds ratio

- DM: Diabetes mellitus

- DOTS: Directly observed treatment strategy

- ELISA: Enzyme linked immune sorbent assay

- g/dl: Gram per deciliter

- HbA1c: Hemoglobin A one c

- HIV: Human immune deficiency virus

- IPAQ: International physical activity questionnaire

- IQR: Interquartile range

- MARS: Medication adherence scale

- $\mathrm{mg} / \mathrm{dl}$ : Milligram per deciliter

- $\mathrm{ng} / \mathrm{dl}$ : Nanogram per deciliter

- SD: Standard deviation

- TB: Tuberculosis

- WHO: World health organization

\section{Declarations}

\section{Ethics approval and consent to participate}

Ethical clearance was obtained from Bahir Dar University College of Medicine and Health sciences ethical review board (Ethical application number CMHS/IRB/124/2018). A support letter was obtained from Amhara national regional state health bureau and respective hospitals. Written informed consent was obtained from each study participant. Study participants with abnormal laboratory findings were linked to the curative segment.

\section{Consent for publication}

Not applicable

\section{Availability of Data and Materials}

The datasets used and/or analyzed during the current study are available from the corresponding author on reasonable request.

\section{Competing interests}

The authors declares that they have no competing interests

\section{Funding}

This research work was financially supported by Bahir Dar University. The funder has no role in design of the study and collection, analysis, and interpretation of data and in writing the manuscript.

\section{Author contribution}

BEF and TEF conceived the experiment; BEF, MBK, WKA, MBK, WKA, AS, SH, TT, FB and TEF performed the experiment, plan the data collection process, analyzed and interpreted the data. BEF, MBK, WKA, MBK, WKA, AS, SH, TT, FB and TEF wrote the manuscript and approved the final draft for publication.

\section{Acknowledgments}

We would like to acknowledge Bahir Dar University for their financial help. Our heartfelt appreciation goes to Amhara national regional state health bureau for their unreserved efforts during the fieldwork. At last but not least our acknowledgments extends to all organizations and individuals that had inputs for this research work.

\section{References}

1. Association AD: Diagnosis and classification of diabetes mellitus. Diabetes care 2010, 33(Supplement 1):S62-S69. 
2. Kerner W, Brückel J: Definition, classification and diagnosis of diabetes mellitus. Experimental and Clinical Endocrinology \& Diabetes 2014, 122(07):384-386.

3. Organization WH: Global report on diabetes. 2016.

4. Hanson MA, Gluckman PD, Ma RC, Matzen P, Biesma RG: Early life opportunities for prevention of diabetes in low and middle income countries. BMC Public Health 2012, 12(1):1025.

5. Cho N, Shaw J, Karuranga S, Huang Y, da Rocha Fernandes J, Ohlrogge A, Malanda B: IDF Diabetes Atlas: Global estimates of diabetes prevalence for 2017 and projections for 2045. Diabetes research and clinical practice 2018, 138:271-281.

6. Abebe N, Kebede T, Addise D: Diabetes in Ethiopia 2000-2016 prevalence and related acute and chronic complications; a systematic review. Afr J Diabetes Med 2017, 25(2):7-12.

7. Organization WH: Financing prevention, testing and treatment of hepatitis in the context of Universal Health Coverage: report from a satellite meeting at the Replenishment Conference of the Global Fund to Fight AIDS, Tuberculosis and Malaria, March 2020. 2020.

8. Datiko D, Hadgu A, Jerene D, Suarez PG: High urban tuberculosis case notification rates can be misleading: evidence from an urban setting in Ethiopia. BMC Public Health 2020, 20(1):1-6.

9. Lönnroth K, Roglic G, Harries AD: Improving tuberculosis prevention and care through addressing the global diabetes epidemic: from evidence to policy and practice. The lancet Diabetes \& endocrinology 2014, 2(9):730-739.

10. Pan S-C, Ku C-C, Kao D, Ezzati M, Fang C-T, Lin H-H: Effect of diabetes on tuberculosis control in 13 countries with high tuberculosis: a modelling study. The lancet Diabetes \& endocrinology 2015, 3(5):323-330.

11. Toniolo A, Cassani G, Puggioni A, Rossi A, Colombo A, Onodera T, Ferrannini E: The diabetes pandemic and associated infections: suggestions for clinical microbiology. Reviews in Medical Microbiology 2019, 30(1):1.

12. Al-Rifai RH, Pearson F, Critchley JA, Abu-Raddad LJ: Association between diabetes mellitus and active tuberculosis: A systematic review and meta-analysis. PloS one 2017, 12(11):e0187967.

13. Sjostrom M, Ainsworth B, Bauman A, Bull F, Hamilton-Craig C, Sallis J: Guidelines for data processing analysis of the International Physical Activity Questionnaire (IPAQ)-Short and long forms. 2005.

14. Fialko L, Garety PA, Kuipers E, Dunn G, Bebbington PE, Fowler D, Freeman D: A large-scale validation study of the Medication Adherence Rating Scale (MARS). Schizophrenia research 2008, 100(1-3):53-59.

15. Calisti L, Tognetti S: Measure of glycosylated hemoglobin. Acta bio-medica: Atenei Parmensis 2005, 76:59-62.

16. Bush B, Shaw S, Cleary P, Delbanco TL, Aronson MD: Screening for alcohol abuse using the CAGE questionnaire. The American journal of medicine 1987, 82(2):231-235.

17. Catignani G, Bieri J: Simultaneous determination of retinol and alpha-tocopherol in serum or plasma by liquid chromatography. Clinical chemistry 1983, 29(4):708-712.

18. Smith J, Butrimovitz G, Purdy W: Direct measurement of zinc in plasma by atomic absorption spectroscopy. Clinical Chemistry 1979 , 25(8):1487-1491.

19. Lewis S, Hardison N, Veillon C: Comparison of isotope dilution mass spectrometry and graphite furnace atomic absorption spectrometry with Zeeman background correction for the determination of plasma selenium. Analytical chemistry 1986, 58(6):1272-1273.

20. Jette A, Davies A, Cleary P, Calkins D, Rubenstein L, Fink A, Kosecoff J, Young R, Brook R, Delbanco T: The Functional Status Questionnaire: reliability and validity when used in primary care. Journal of general internal medicine 1986, 1(3):143.

21. Tiyyagura SR, Smith DA: Standard lipid profile. Clinics in laboratory medicine 2006, 26(4):707-732.

22. Pinnell AE, Northam BE: New automated dye-binding method for serum albumin determination with bromcresol purple. Clinical chemistry 1978, 24(1):80-86.

23. Alisjahbana B, Sahiratmadja E, Nelwan EJ, Purwa AM, Ahmad Y, Ottenhoff THM, Nelwan RHH, Parwati I, Meer JWMvd, Crevel Rv: The Effect of Type 2 Diabetes Mellitus on the Presentation and Treatment Response of Pulmonary Tuberculosis. Clinical Infectious Diseases 2007, 45(4):428-435.

24. Wang C, Yang C, Chen H, Chuang S, Chong I, Hwang J, Huang M: Impact of type 2 diabetes on manifestations and treatment outcome of pulmonary tuberculosis. Epidemiology \& Infection 2009, 137(2):203-210.

25. Ruslami R, Nijland HM, Adhiarta IGN, Kariadi SH, Alisjahbana B, Aarnoutse RE, van Crevel R: Pharmacokinetics of antituberculosis drugs in pulmonary tuberculosis patients with type 2 diabetes. Antimicrobial agents and chemotherapy 2010, 54(3):1068-1074.

26. Magee MJ, Foote M, Ray SM, Gandhi NR, Kempker RR: Diabetes mellitus and extrapulmonary tuberculosis: site distribution and risk of mortality. Epidemiology and Infection 2016, 144(10):2209-2216.

27. Zheng C, Hu M, Gao F: Diabetes and pulmonary tuberculosis: a global overview with special focus on the situation in Asian countries with high TB-DM burden. Global health action 2017, 10(1):1264702. 
28. Gil-Santana L, Almeida-Junior JL, Oliveira CA, Hickson LS, Daltro C, Castro S, Kornfeld H, Netto EM, Andrade BB: Diabetes is associated with worse clinical presentation in tuberculosis patients from Brazil: a retrospective cohort study. PloS one 2016, 11(1):e0146876.

29. Siddiqui AN, Khayyam KU, Sharma M: Effect of Diabetes Mellitus on Tuberculosis Treatment Outcome and Adverse Reactions in Patients Receiving Directly Observed Treatment Strategy in India: A Prospective Study. BioMed research internationa/ 2016, $2016: 7273935$.

30. Skowroński M, Zozulińska-Ziółkiewicz D, Barinow-Wojewódzki A: Tuberculosis and diabetes mellitus-an underappreciated association. Archives of medical science: AMS 2014, 10(5):1019.

31. Feleke BE, Alene GD, Feleke TE, Motebaynore Y, Biadglegne F: Clinical response of tuberculosis patients, a prospective cohort study. PloS one 2018, 13(1):e0190207.

32. Mahishale V, Avuthu S, Patil B, Lolly M, Eti A, Khan S: Effect of poor glycemic control in newly diagnosed patients with smear-positive pulmonary tuberculosis and type-2 diabetes mellitus. Iranian journal of medical sciences 2017, 42(2):144.

33. Dooley KE, Chaisson RE: Tuberculosis and diabetes mellitus: convergence of two epidemics. The Lancet Infectious Diseases 2009, 9(12):737746.

34. Muñoz-Torrico M, Caminero-Luna J, Migliori GB, D’Ambrosio L, Carrillo-Alduenda JL, Villareal-Velarde H, Torres-Cruz A, Flores-Vergara H, Martínez-Mendoza D, García-Sancho C et al: Diabetes is Associated With Severe Adverse Events in Multidrug-Resistant Tuberculosis. Archivos de Bronconeumología (English Edition) 2017, 53(5):245-250.

35. Van Crevel R, Koesoemadinata R, Hill P, Harries A: Clinical management of combined tuberculosis and diabetes. The International Journal of Tuberculosis and Lung Disease 2018, 22(12):1404-1410.

36. Hurrle S, Hsu WH: The etiology of oxidative stress in insulin resistance. biomedical journal 2017, 40(5):257-262.

37. Devi TR, Hijam D, Dubey A, Debnath S, Oinam P, Devi NT, Singh WG: Study of serum zinc and copper levels in type 2 diabetes mellitus. International Journal of Contemporary Medical Research 2016, 3(4):1036-1040.

38. Jayawardena R, Ranasinghe P, Galappatthy P, Malkanthi R, Constantine G, Katulanda P: Effects of zinc supplementation on diabetes mellitus: a systematic review and meta-analysis. Diabetology \& metabolic syndrome 2012, 4(1):13.

39. Choi HS, Kim K-A, Lim C-Y, Rhee SY, Hwang Y-C, Kim KM, Kim KJ, Rhee Y, Lim S-K: Low Serum Vitamin D Is Associated with High Risk of Diabetes in Korean Adults. The Journal of Nutrition 2011, 141(8):1524-1528.

40. Feleke BE, Feleke TE, Mekonnen D, Beyene MB: Micronutrient levels of tuberculosis patients during the intensive phase, a prospective cohort study. Clinical nutrition ESPEN 2019, 31:56-60.

41. Vrieling F, Ronacher K, Kleynhans L, Van Den Akker E, WalzI G, Ottenhoff TH, Joosten SA: Patients with concurrent tuberculosis and diabetes have a pro-atherogenic plasma lipid profile. EBioMedicine 2018, 32:192-200.

42. Feleke BE, Feleke TE, Biadglegne F: Nutritional status of tuberculosis patients, a comparative cross-sectional study. BMC pulmonary medicine 2019, 19(1):182.

43. de Grauw WJ, van de Lisdonk EH, Behr RR, van Gerwen WH, van den Hoogen HJ, van Weel C: The impact of type 2 diabetes mellitus on daily functioning. Family Practice 1999, 16(2):133-139.

\section{Questionnaire}

The questionnaire of the study were taken from the following references

- Sjostrom M, Ainsworth B, Bauman A, Bull F, Hamilton-Craig C, Sallis J: Guidelines for data processing analysis of the International Physical Activity Questionnaire (IPAQ)-Short and long forms. 2005.

- Fialko L, Garety PA, Kuipers E, Dunn G, Bebbington PE, Fowler D, Freeman D: A large-scale validation study of the Medication Adherence Rating Scale (MARS). Schizophrenia research 2008, 100(1-3):53-59

- Bush B, Shaw S, Cleary P, Delbanco TL, Aronson MD: Screening for alcohol abuse using the CAGE questionnaire. The American journal of medicine 1987, 82(2):231-235.

- Jette A, Davies A, Cleary P, Calkins D, Rubenstein L, Fink A, Kosecoff J, Young R, Brook R, Delbanco T: The Functional Status Questionnaire: reliability and validity when used in primary care. Journal of general internal medicine 1986, 1(3):143.

\section{Figures}




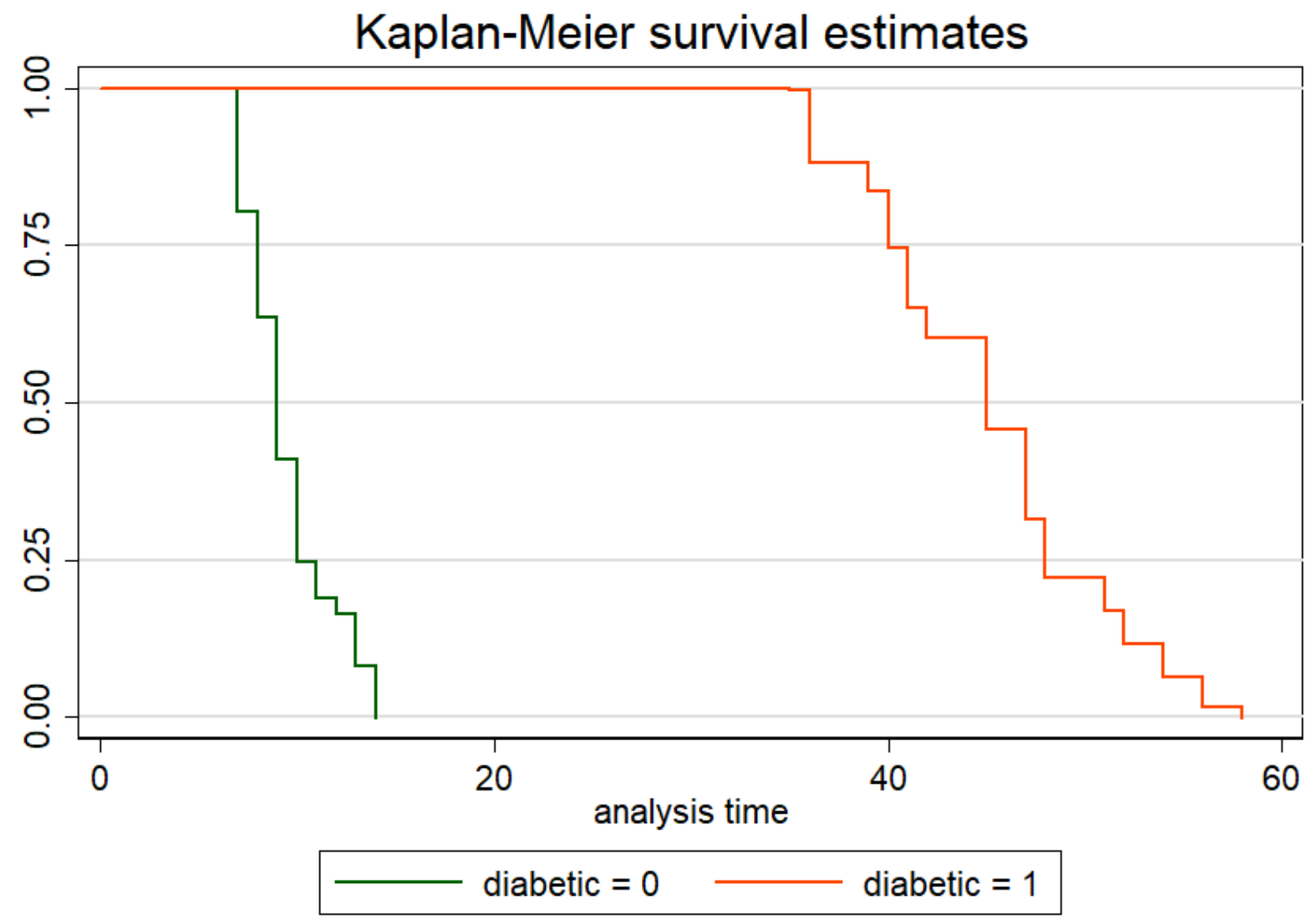

Figure 1

The median time of clinical response in DM free TB patients was 9 days [IQR 2 days]

\section{Supplementary Files}

This is a list of supplementary files associated with this preprint. Click to download.

- STROBEchecklistcohort.docx 